\title{
Temperature and Photoperiod Effects on Fuchsia $\times$ hybrida Morphology
}

\author{
John E. Erwin', Royal D. Heins, and Roar Moe ${ }^{2}$ \\ Department of Horticulture, Michigan State' University, East Lansing, MI 48824-1112
}

Additional index words. thermoperiodism, thermomorphogenesis, stem elongation, branching, leaf area, photoperiod, DIF, phytochrome

\begin{abstract}
Fuchsia $\times$ hybrids 'Dollar Princess' plants were grown under 35 day/night temperature (DT/NT) environments ranging from 10 to 30C over 2 years. Plants were grown under short days (SD) (9-hour 15-minute photoperiod) or long days (LD) (9-hour 15-minute photoperiod plus a 4-hour night interruption) within each environment. The influence of temperature on Fuchsia stem elongation and leaf expansion was best described by the relationship or difference (DIF) between DT and NT (DT - NT) rather than actual DT and NT between 10 and 25C. Both internode length and leaf area increased linearly as DIF increased from -15 to $+15 \mathrm{C}$ with DT and NT between 10 and $25 \mathrm{C}$. Internode length increased 0.129 and $0.071 \mathrm{~cm} / 1 \mathrm{C}$ increase in DIF for LD- and SD-grown plants, respectively. Individual leaf area increased 0.52 and $0.40 \mathrm{~cm}^{2} / 1 \mathrm{C}$ increase in DIF for LD- and SD-grown plants, respectively. DT or NT above $24 \mathrm{C}$ reduced stem elongation and leaf expansion, regardless of DIF. The response of stem elongation and leaf expansion to DIF was greater on a percent basis when plants were grown under SD and LD, respectively. On an absolute basis, both internode length and leaf area were greater on LD-grown plants. Branching increased as average daily temperature decreased from 25 to $12 \mathrm{C}$. Photoperiod did not affect branching.
\end{abstract}

\begin{abstract}
Temperature affects plant morphology in many plant species, i.e., plants are thermomorphogenic (Erwin, 1991; Erwin et al., 1989; Went, 1952, 1957). The effects of temperature on plant growth have historically been ascribed solely to actual DT and NT (Went, 1952, 1957). Recent results on Lilium longiflorum showed that stem elongation and leaf orientation were influenced primarily by DT - NT rather than actual DT and NT between 10" and 30C (Erwin and Heins, 1990; Erwin et al., 1989). As DT increased relative to NT, i.e., as DIF increased, Lilium stem elongation increased and leaf orientation became more upright. Similarly, stem elongation in Streptocaipus nobilis, Xanthium stromium, Lycopersicum esculentum, Zea mays, Salvia splendens, Impatiens walleriana, Nephrolepis txaltata (Erwin, 1991; unpublished data), Euphorbia pulcherrima (Berghage, 1989), Dendranthema $\times$ grandiflorum (Karlsson et al., 1989), and Campanula isophylla (Moe and Heins, 1991) was best described by DIF and increased as DIF increased within the 10 to $30 \mathrm{C}$ temperature range.
\end{abstract}

Correlative evidence suggests that thermomorphogenic responses may be mediated by or interact with phytochrome to elicit growth responses (Erwin, 1991; Erwin et al., 1989; Moe and Heins, 1991). Plants grown under positive DIF environments (higher DT than NT) appear morphologically similar to plants irradiated with light of a low red $(\mathrm{R})(660 \mathrm{~nm})$ : far red (FR) $(720 \mathrm{~nm})$ ratio; plants have long internodes and an upright leaf orientation. Conversely, plants grown under negative DIF environments (higher NT than DT) appear similar to plants irradiated with light having a high $\mathrm{R}$ : FR ratio; plants have short internodes and a horizontal leaf orientation.

In addition to indirect evidence for phytochrome involve-

Received for publication 17 May 1990. We appreciate the assistance of Brian Kovanda, Joy Hind, Martin Stockton, Mark Smith, and Wendy Cole. Fuchsia plants were donated by Green Circle Growers, Oberlin, Ohio. We acknowledge the Michigan Agriculture Experiment Station and the American Floral Endowment for support of this project. The cost of publishing this paper was defrayed in part by the payment of page charges. Under postal regulations, this paper therefore must be hereby marked advertisement solely to indicate this fact.

'Current address: Dept. of Horticultural Science, Univ. of Minnesota, 1970 FolweI1 Ave., St. Paul, MN 55108.

${ }^{2}$ Current address: Dept. of Horticulture, Agricultural Univ. of Norway, Aas, Norway. ment, there is an interaction between DIF and light quality (Erwin, 1991; Moe and Heins, 1991). Incandescent light (low R : FR ratio) during the night can overcome inhibition of stem elongation by a negative DIF environment in Campanula isophylla (Moe and Heins, 1991). In contrast, fluorescent light (high R : FR ratio) during the night enhanced the inhibition of Campanula elongation that resulted from growing plants in a negative DIF environment. An interaction between light quality and DIF suggests that phytochrome may be involved in perceiving and/or interacting with DIF to affect plant growth,

An understanding of how photoperiod and DIF interact to affect plant stem elongation may result in alternative methods of plant height control in controlled environments that use light and/or temperature to control plant growth. The objective of the research conducted in this study was to determine if DIF and photoperiod extension through night interruption lighting (NI) interact to affect plant morphology. Fuchsia $\times$ hybrida was chosen for these studies because it exhibits a strong stem elongation response to DT and NT (Tageras, 1979), and the effect of photoperiod on Fuchsia stem elongation has been studied extensively (Vince-Prue, 1977).

\section{Materials and Methods}

1988 Experiments. Fuchsia $\times$ hybrida 'Dollar Princess' (fuchsia) rooted cuttings were planted on 2 Jan. 1988 in 12.7$\mathrm{cm}\left(390 \mathrm{~cm}^{3}\right)$ plastic pots containing a soilless medium consisting of equal parts of sphagnum peat, perlite, and vermiculite. One plant was planted in each pot. Plants were grown for 2 weeks in a glasshouse under natural photoperiodic conditions with air maintained at $20 \pm 2 \mathrm{C}$. Plants then were selected for uniformity based on number of leaves and lateral shoots and on plant height before being moved to glasshouses maintained at $12,16,20$, and 24C. Half of the plants (24) within each glasshouse were grown under a SD photoperiod of $9 \mathrm{~h} 15 \mathrm{~min}$ daylight. The other half of the plants received a LD photoperiod of 9 h 15 min daylight plus NI from 2200 to $0200 \mathrm{HR}$, all delivered with incandescent lamps at an irradiance of $2 \mu \mathrm{mol} \cdot \mathrm{m}^{-2} \cdot \mathrm{s}^{-1}$

Abbreviations: ADT, average daily temperature; DIF, difference; DT/NT, day/ night temperature; FR, far red; LD, long day; NI, night interruption; R, red; $\mathrm{SD}$, short day. 
Plants were moved along the four glasshouses at 0800 and $1700 \mathrm{HR}$ each day to yield a total of 16 DT/NT environments within each photoperiod. Each environmental treatment contained six samples. Movement of plant required $15 \mathrm{~min}$. An opaque curtain was pulled over the plants at $1715 \mathrm{HR}$ after they were moved at $1700 \mathrm{HR}$ and was retracted at $0800 \mathrm{HR}$ to provide a photoperiod paralleling the thermoperiod. Light pollution between LD and SD plants within a glasshouse section was eliminated by pulling an opaque curtain between plants at $1715 \mathrm{HR}$ and retracting the curtain at $0800 \mathrm{HR}$. The terminal shoot was pinched at the initiation of the "environmental treatments.

Glasshouse temperatures were controlled using a glasshouse climate control computer and monitored by a datalogger using iron/constantan thermocouples. Actual glasshouse section temperatures were determined by thermocouple readings taken every $10 \mathrm{sec}$ by a datalogger, which then calculated mean glasshouse temperatures every $2 \mathrm{~h}$. Average DT and NT were calculated for each environmental treatment based on bihourly temperature means and the length of time that plants were grown within an environment. All plants were within $2 \mathrm{~m}$ of thermocouples during the experiment. Average DT and/or NT did not vary by more than $2 \mathrm{C}$ from temperature setpoints over the course of the experiment (Table 1). Treatments are described by treatment setpoints throughout the paper. Actual temperatures were used in regression analysis.

Internode length, leaf length and width, and lateral shoot count were collected at anthesis on plants grown under LD and after 78 days on plants grown under SD. Internode length was collected from the second internode above the marked leaf pair. A lateral shoot was defined as any axillary break with two or more nodes. Leaf length and width were collected from a leaf at the base of the second internode above the marked leaf pair. Since leaves were elliptic in shape, leaf area was estimated by the formula for the surface area of a standard ellipse: leaf area $=($ leaf length $/ 2) \times($ leaf width/2) $\times 3.718$.

1989 Experiment. The 1988 experiment was replicated with the following changes: 1) Temperature treatments were started on 22 Oct. 1988.2) Terminal shoots were removed twice before the start of treatments. 3) Glasshouse sections were maintained at $10,15,20$, and $25 \mathrm{C}$. 4) Three additional temperature environments were added: 10C DT/30C NT, 30C DT/10C NT, and constant 30C. 5) Data were collected after 74 days on plants grown under SD. 6) The uppermost unfolded leaf pair on each plant was marked with black ink to identify the developmental

Table 1. Temperature setpoints and actual average DT and NT (DT/ NT) for environmental treatments for 1988 and 1989.

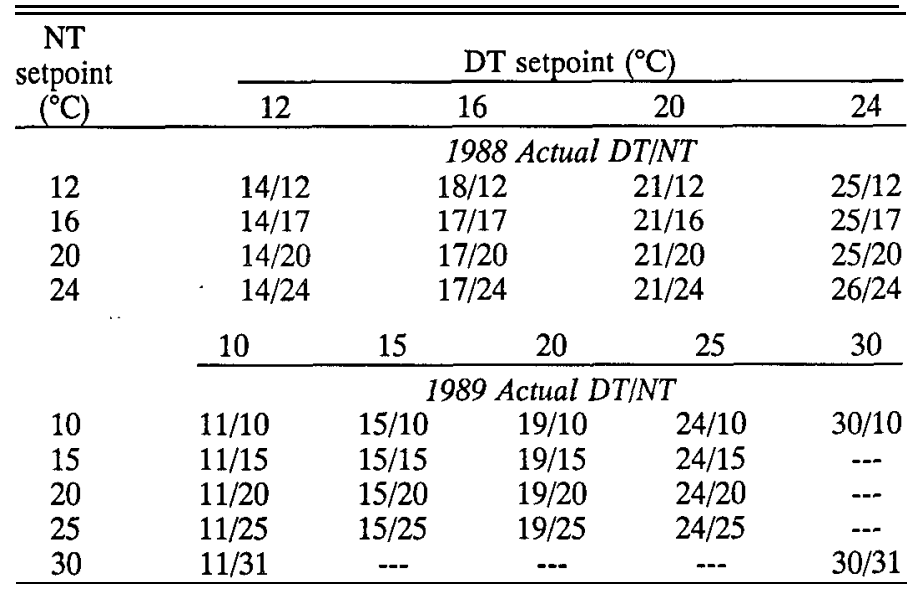

stage of each plant when the experiment was initiated. 7) No lateral shoot counts were taken.

Data analysis. Data were analyzed for both experiments by analysis of variance (ANOVA) using a $4 \times 4 \times 2$ factorial design with DT, NT, and photoperiod as the main factors. Interaction terms could not be evaluated through ANOVA as each temperature treatment constituted a single replicate. The relative importance of individual environmental characteristics in affecting morphological development was evaluated through multilinear regression analysis. Selection of functions was based on $r^{2}$, Mallow's $\mathrm{C}_{\mathrm{p}}$ (Draper and Smith, 1981), significance of parameters, and visual inspection of the fit of the regression function with the data.

The functional relationships between DIF and internode length and leaf area were described with linear regression analysis. Significant. differences between years, and interactions between DIF and photoperiod were evaluated by analyzing differences between intercepts and slopes, respectively, of regression functions. Statistical analysis of differences between slopes and elevations among regression functions followed the procedure reported by Snedecor and Cochran (1967).

\section{Results}

Internode length. Internode length in 'Dollar Princess' fuchsia was affected by photoperiod and temperature. Internode length, averaged over all treatments, was $142 \%$ greater on plants grown under LD than on plants grown under SD (Table 2). Absolute differences ranged from 0.1 to $3.4 \mathrm{~cm}$.

Internode length increased as DT increased and/or NT decreased (Table 2), but was best described by DIF (Fig. 1). Internode length increased as DIF increased when actual temperatures ranged from 12 to $24 \mathrm{C}$ in the 1988 experiment (Fig. 1). Internode length increased from 2.5 to $6.2 \mathrm{~cm}$ as DIF increased from -15 to $15 \mathrm{C}$ on LD-grown plants in the 1989 experiment (Table 2). Increasing DT above $25 \mathrm{C}$ reduced fuchsia internode length, regardless of DIF (Table 2). For example, on LD-grown plant, internode length decreased from 6.2 to $4.1 \mathrm{~cm}$ as DT increased from 25 to $30 \mathrm{C}$ with a $10 \mathrm{C}$ NT even though DIF increased from 15 to $20 \mathrm{C}$.

Slopes of regression functions $\left(b_{1}\right)$, representing the effect of DIF on internode length when temperatures ranged from 10 and 25C, were not significantly different between the 1988 and 1989 experiments (Table 3). Therefore, data from each photoperiod were combined across years by normalizing data based on the difference in elevation $\left(b_{0}\right)$ between the functions (Fig. 2). This was done by adding $0.266(1.861-1.595)$ to $1988 \mathrm{SD}$ means and $-0.447(4.281-4.728)$ to 1988 LD means.

DIF and photoperiod interacted to affect stem elongation, as shown by a significant difference between slopes $\left(b_{1}\right)$ of the functions in Fig. 2, i.e., between LD and SD plants (Table 3). Plants grown under SD showed a lesser response to DIF on an absolute basis but a greater response to DIF on a percent basis than plants grown under LD. For instance, internode length increased $326 \%$ and $224 \%$ as DIF increased from -15 to $15 \mathrm{C}$ when plants were grown under SD and LD, respectively.

Leaf size. Individual leaf size was affected by photoperiod and temperature. Leaf area, averaged over all treatments, was $22 \%$ greater on plants grown under LD than on plants grown under SD (Table 4). Absolute differences ranged from 0.1 to $7.0 \mathrm{~cm}^{2} /$ leaf.

As with stem elongation, leaf area increased as DT increased and/or NT decreased, but was best described by DIF (Fig. 3). Individual leaf area increased from 7.3 to $15.4 \mathrm{~cm}^{2}(+111 \%)$ 
Table 2. The effect of DT, NT, and photoperiod on Fuchsia $\times$ hybrida 'Dollar Princess' internode length at anthesis. LD was delivered as a 9-h 15-min photoperiod of daylight plus a 4-h night interruption using incandescent lamps at an irradiance of 2 $\mu \mathrm{mol} \cdot \mathrm{m}^{-2} \cdot \mathrm{s}^{-1}$. SD was delivered as a 9-h $15-\mathrm{min}$ photoperiod only. Data presented are from the 1989 experiment.

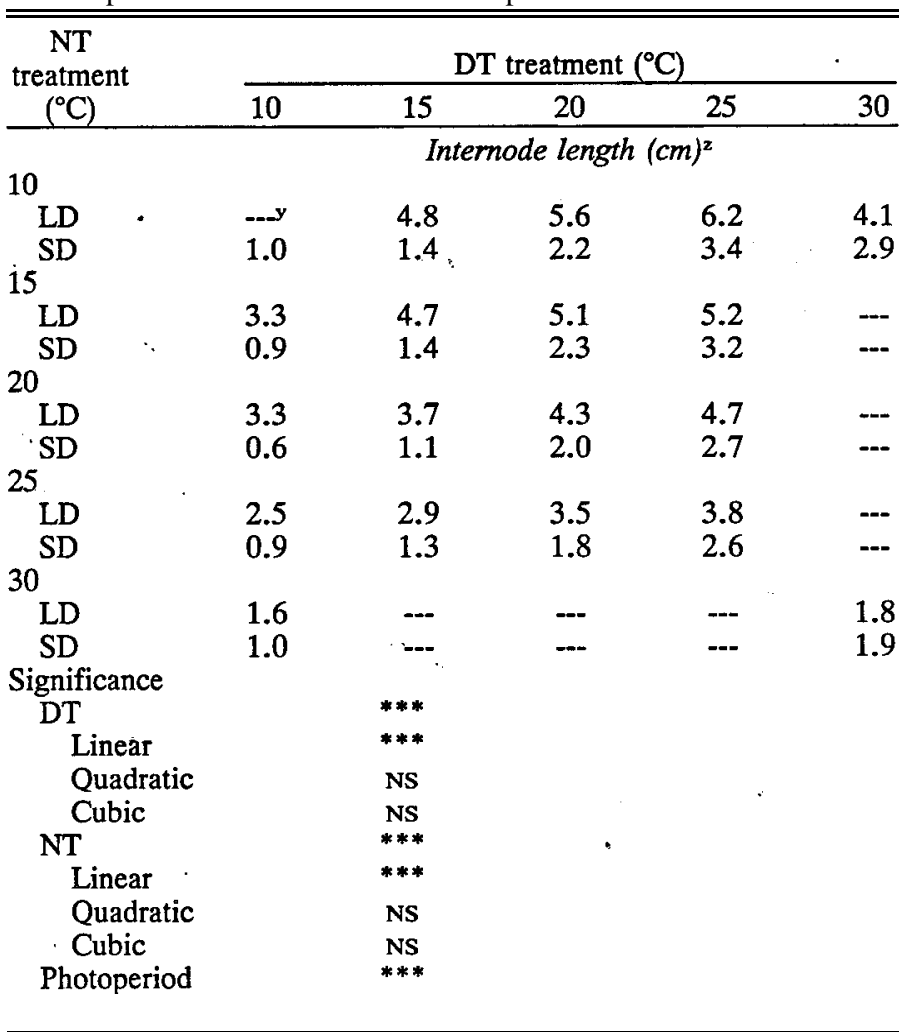

${ }^{2}$ Numerals represent treatment means.

'Dashes indicate missing treatment means.

***, Ns Significance of 1988 and 1989 experiments combined at $P=$ 0.001 or not significant, respectively.

as DIF increased from -15 to $15 \mathrm{C}$ on LD-grown plants in the 1989 experiment. As with stem elongation, DT above $24 \mathrm{C}$ reduced leaf expansion (Table 4). Increasing DT from 25 to $30 \mathrm{C}$ decreased leaf area from 15.4 to $7.9 \mathrm{~cm}^{2}(-49 \%)$ on LD-grown plants even though DIF increased from 15 to $20 \mathrm{C}$.

Slopes of regression functions $\left(b_{1}\right)$, representing the response of leaf expansion to DIF, were not significantly different between years within photoperiod treatments (Table 5). Therefore, data frorn each photoperiod were combined across years by normalizing data based on differences in elevation $\left(b_{0}\right)$ between functions (Fig. 3). This was done by adding 2.56 (12.949$10.390)$ to $1989 \mathrm{SD}$ means and $-1.86(12.68-14.54)$ to 1988 LD means.

Slopes of functions representing the response of leaf expansion to DIF between LD- and SD-grown plants were significantly different, indicating an interaction between DIF and photoperiod (Table 4). In contrast to stem elongation, plants grown under LD showed a greater response to DIF on a percent basis (Table 4 and Fig. 3). Leaf area increased 249\% and 289\% as DIF increased from - 15 to $15 \mathrm{C}$ on SD- and LD-grown plants, respectively.

Branching. Lateral shoot development was primarily influenced by average daily temperature (ADT). Lateral branch number per plant decreased exponentially as ADT increased from

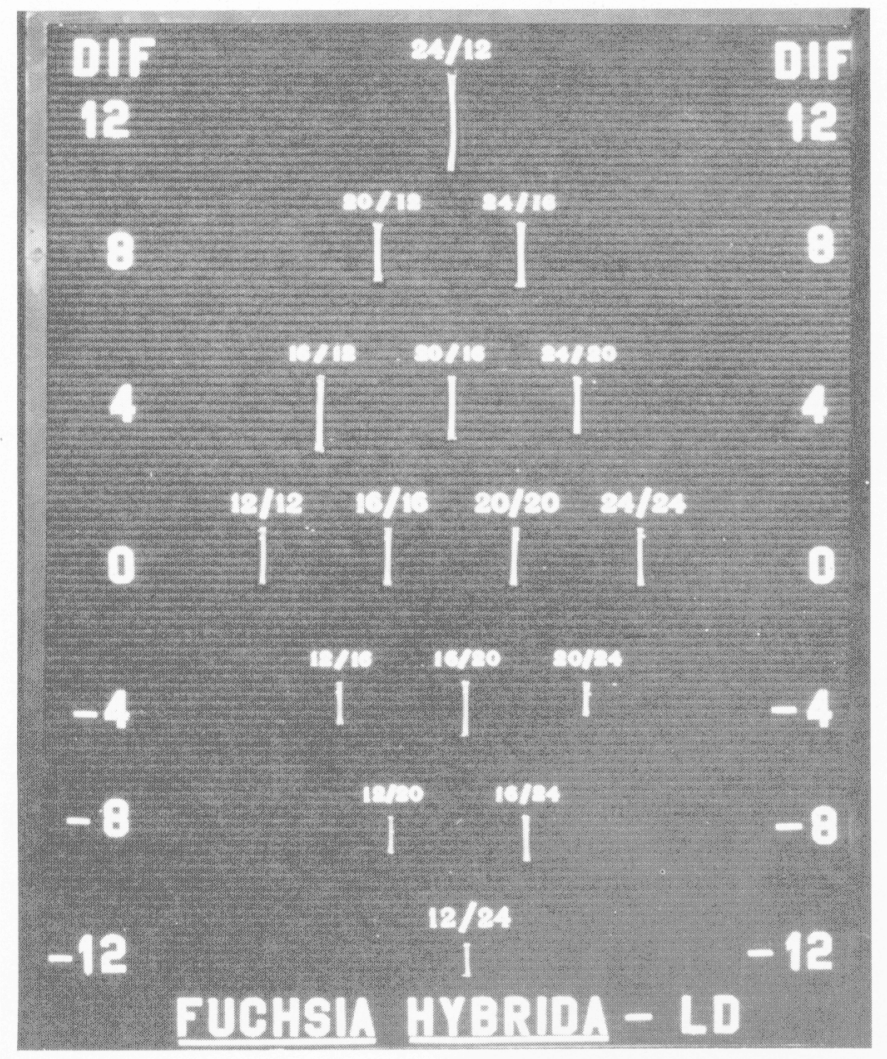

Fig. 1. Effect of DIF between DT and NT (DT - NT) on internode length of Fuchsia $\times$ hybrids 'Dollar Princess' plants grown during 1989. Plants were grown under LD conditions, i.e., a 9-h 15-min photoperiod plus a 4-h NI using incandescent lighting at an irradiance of $2 \mu \mathrm{mol} \cdot \mathrm{m}^{-2} \cdot \mathrm{s}^{-1}$.

Table 3. Regression coefficients calculated to predict internode length of Fuchsia $\times$ hybrida 'Dollar Princess' plants from experiments conducted during 1988 (88) and 1989 (89) to study the effects of DT, NT, and photoperiod on plant morphology. Internode length was described as a function of DIF, where internode length $=b_{0}+b_{t}$ $\times$ DIF. Slopes and intercepts were evaluated using a techinque outlined by Snedecor and Cochran (1967).

\begin{tabular}{|c|c|c|c|c|c|c|c|c|c|}
\hline \multirow[b]{3}{*}{ Coefficients } & \multicolumn{5}{|c|}{ Raw data } & \multirow{2}{*}{\multicolumn{4}{|c|}{$\begin{array}{l}\text { Normalized data } \\
\text { regression }\end{array}$}} \\
\hline & \multicolumn{2}{|c|}{ SD } & \multicolumn{3}{|c|}{ LD } & & & & \\
\hline & 88 & 89 & & 88 & 89 & SD & & $\mathrm{L}$ & \\
\hline$b_{o}$ & 1.595 & 1.861 & & 728 & 4.281 & 1.871 & & 4.7 & \\
\hline$b_{1}$ & 0.067 & 0.073 & 0.1 & 124 & 0.132 & 0.071 & & 0.1 & \\
\hline$r^{2}$ & 0.884 & 0.572 & & 696 & 0.964 & 0.644 & & 0.8 & \\
\hline \multicolumn{10}{|c|}{ Comparison of slopes } \\
\hline \multicolumn{6}{|c|}{ Raw data: 88 SD vs. 89 SD } & $(\mathrm{df}=$ & , & 31) & \\
\hline \multicolumn{4}{|c|}{ Raw data: 88 LD vs. 89 LD } & $\mathrm{F}$ & $=3.6$ & $(\mathrm{df}=$ & & 30) & NS \\
\hline \multicolumn{4}{|c|}{ Normalized data: SD vs. LD } & $\mathrm{F}$ & $=36.9$ & $(\mathrm{df}=$ & , & 61) & $* * *$ \\
\hline \multicolumn{10}{|c|}{ Comparison of intercepts } \\
\hline \multirow{2}{*}{\multicolumn{4}{|c|}{$\begin{array}{l}\text { Raw data: } 88 \text { SD vs. } 89 \text { SD } \\
\text { Raw data: } 88 \text { LD vs. } 89 \text { LD }\end{array}$}} & & $=9.2$ & $(\mathrm{df}=$ & , & & $* * *$ \\
\hline & & & & & $=12.3$ & $(\mathrm{df}=$ & 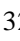 & & \\
\hline \multicolumn{4}{|c|}{ Normalized data: SD vs. LD } & $\mathrm{F}$ & $=441.8$ & $(\mathrm{df}$ & & $65)$ & $* * *$ \\
\hline
\end{tabular}

12 to $24 \mathrm{C}$, regardless of photoperiod (Fig. 4). For instance, lateral branch number per plant decreased from 11.5 to 4.5 branches $(-61 \%)$ as ADT increased from 12 to 24C on LDgrown plants in the 1988 experiment. Photoperiod had no significant effect on lateral branching (Fig. 4). 


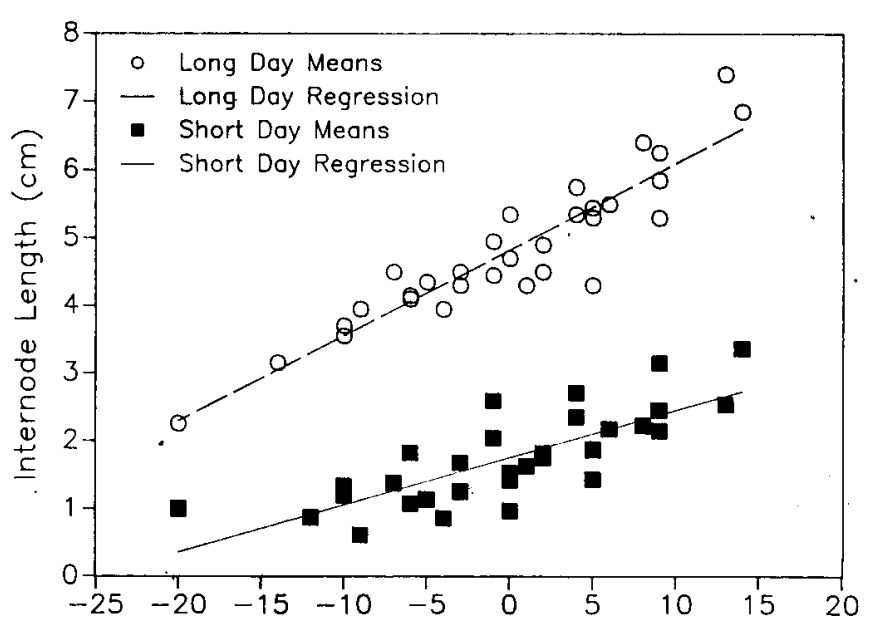

Difference Between Day And Night Temperature $\left({ }^{\circ} \mathrm{C}\right)$

Fig. 2. Effect of DIF between DT and NT (DT - NT) on internode length of Fuchsia $\times$ hybrida 'Dollar Princess' plants grown under LD (9-h 15-min photoperiod plus 4-h NI using incandescent lamps at an irradiance of $\left.2 \mu \mathrm{mol} \cdot \mathrm{m}^{-2} \cdot \mathrm{s}^{-1}\right)$ and SD (9-h 15 -min photoperiod). Data were normalized across 1988 and 1989 experiments within photoperiod treatments. Regression function calculated from LD data: internode length $(\mathrm{cm})=4.727+(0.129 \times \mathrm{X})\left(r^{2}=0.87\right)$; from SD data: internode length $(\mathrm{cm})=1.871+(0.071 \times \mathrm{X})\left(r^{2}=\right.$ $0.64)$.

\section{Discussion}

Fuchsia internode length was a function of the relationship between DT and NT within a limited temperature range. Fuchsia internode length increased as DT increased and NT decreased, as has been reported previously on other plant species (Berghage, 1989; Erwin et al., 1989; Karlsson et al., 1989; Moe and Heins, 1991; Tageras, 1979). The effect of temperature on fuchsia stem elongation could be described more comprehensively with the term DIF than by actual DT or NT, as previously shown for Lilium (Erwin and Heins, 1990; Erwin et al., 1989) and Campanula isophylla (Moe and Heins, 1991). While Went (1957) suggested that plant stem elongation was primarily influenced by DT, our measurements of internode lengths from photographic plates of Pisum sativum plants, which were the basis of Went's conclusions showed internode length was strongly influenced by DIF.

The physiological basis for the effect of DIF on stem elongation is believed to involve gibberellins (Erwin et al., 1989; Zieslin and Tsujita, 1988). Application of gibberellins $\left(\mathrm{GA}_{4+7}\right)$ to Lilium bulbs before planting overcame subsequent inhibition of stem elongation by a negative DIF environment (Zieslin and Tsujita, 1988). Similarly, Moe and Heins (1991) showed that spray applications of $\mathrm{GA}_{3}$ overcame inhibition of Campanula i.rophylla stem elongation when plants were grown in a negative DIF environment. In contrast, application of a GA synthesis inhibitor, alpha-cyclopropyl-alpha-(4-methoxyphenyl)-5-pyrimidinemethanol (aneymidol), resulted in a greater percent decrease in stem elongation of positive-DIF-grown plants than negative-DlFgrown Lilium plants (Erwin et al., 1989). An interaction between DIF and GA synthesis on stem elongation is, therefore, probable.

Further evidence for GA involvement can be seen with the effects of DIF on plant sex expression. Gibberellins (Jones and Zeevaart, 1980; Pharis and King, 1985) and DIF (Erwin, 1991) affect plant sex expression in the dioecious family Cucur-bita-
Table 4. The effect of DT, NT, and photoperiod on Fuchsia $\times$ hybrids 'Dollar Princess' single leaf area at anthesis, 1989. LD was delivered as a 9-h 15-min photoperiod of daylight plus a 4-h NI using incandescent lamps at an irradiance of $2 \mu \mathrm{mol} \cdot \mathrm{m}^{-} \cdot{ }^{2} \cdot \mathrm{s}-{ }^{1} \mathrm{~S} D$ was delivered as a 9-h $15-\mathrm{min}$ photoperiod only. Leaf area was calculated by measuring leaf length and width and calculating the area of an ellipse, i.e., leaf area $=($ width $/ 2) \times($ length $/ 2) \times 3.78$.

\begin{tabular}{|c|c|c|c|c|c|}
\hline \multirow{2}{*}{$\begin{array}{c}\mathrm{NT} \\
\text { treatment } \\
\left({ }^{\circ \mathrm{c})}\right) \\
\end{array}$} & \multicolumn{5}{|c|}{ DT treatment ("C) } \\
\hline & 10 & 15 & 20 & 25 & 30 \\
\hline & \multicolumn{5}{|c|}{ Leaf area $\left(\mathrm{cm}^{2}\right)^{z}$} \\
\hline \multicolumn{6}{|l|}{10} \\
\hline LD & $--y$ & 18.4 & 16.6 & 15.4 & 7.9 \\
\hline SD & 8.9 & 11.4 & 10.9 & 12.1 & 7.1 \\
\hline \multicolumn{6}{|l|}{15} \\
\hline LD & 10.3 & 13.5 & 18.5 & 15.5 & --- \\
\hline SD & 8.8 & 9.4 & 14.8 & 12.8 & --- \\
\hline \multicolumn{6}{|l|}{20} \\
\hline LD & 7.4 & 10.1 & 13.7 & 12.7 & --- \\
\hline SD & 6.8 & 9.4 & 12.0 & 10.8 & --- \\
\hline \multicolumn{6}{|l|}{25} \\
\hline LD & 7.3 & 8.5 & 10.0 & 10.8 & --- \\
\hline SD & 5.9 & 7.4 & 8.7 & 9.0 & --- \\
\hline \multicolumn{6}{|l|}{30} \\
\hline LD & 4.3 & --- & --- & --- & 3.4 \\
\hline SD & 3.9 & --- & --- & --- & 3.5 \\
\hline \multicolumn{6}{|l|}{ Significance } \\
\hline D T & & $* w$ & & & \\
\hline Linear & & $* *$ & & & \\
\hline Quadratic & & NS & & & \\
\hline Cubic & & NS & & & \\
\hline NT & & & & & \\
\hline Linear & & $* * *$ & & & \\
\hline Quadratic & & NS & & & \\
\hline Cubic & & NS & & & \\
\hline Photoperiod & & & & & \\
\hline
\end{tabular}

'Numerals represent treatment means.

${ }^{\mathrm{Y}}$ Dashes indicate missing treatment mean.

*** ${ }^{\mathrm{NS}} \mathrm{Si}$ ificance of both 1988 and 1989 experiments combined at $P$ $=0.001$ or not significant, respectively.

ceae. Exogenous application of GA typically causes maleness (Jones and Zeevaart, 1980; Pharis and King, 1985). In contrast, application of GA synthesis inhibitors induces femaleness (Halevy and Rudich, 1967; Pharis and King, 1985). Plants grown in a positive DIF environment have more male than female flowers. Conversely, plants grown under a zero or negative DIF environment have equal or more female than male flowers (Erwin, 1991). Although other factors can influence sex expression in Cucurbitaceae, such as ethylene, these results, combined with previous data, provide additional evidence that a positive DIF environment may promote GA synthesis and/or that a zero or negative DIF environment may reduce GA synthesis. Alternatively, a zero or negative DIF environment may stimulate synthesis of an elongation inhibitor or promote GA degradation compared to a positive DIF environment.

Stem elongation on reproductive (LD) plants was greater than on vegetative (SD) plants. This was not unexpected, as fuchsia internode elongation is affected by three photoperiod-related factors: 1) fuchsia is an LD plant and stem elongation increases after flower induction (Wilkins, 1985); 2) internode length increases as photoperiod increases (Wilkins, 1985); and 3) internode length increases as the $\mathrm{R}$ : FR content of the last light exposure before darkness decreases (Vince-Prue, 1977). Irradiating plants with NI of incandescent lamps (low R : FR), as 


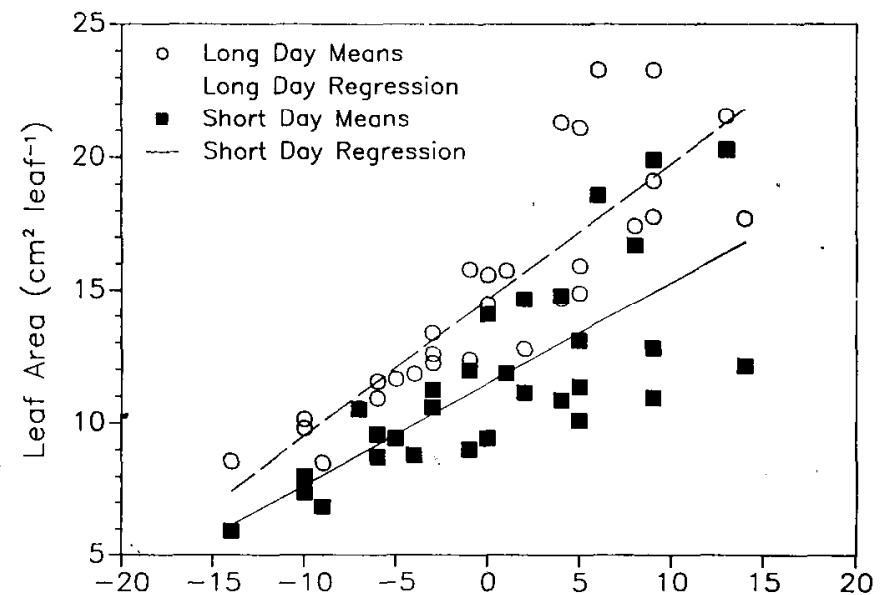

Difference Between Doy And Night Temperature $\left({ }^{\circ} \mathrm{C}\right)$

Fig. 3. Effect of DIF between DT and NT and photoperiod on leaf area of Fuchsia $\times$ hybrids 'Dollar Princess' plants grown under LD (9-h 15-min photoperiod plus 4-h NI using incandescent lamps at an irradiance of $2 \mu \mathrm{mol} \cdot \mathrm{m}^{-2} \cdot \mathrm{s}^{-1}$ ) and SD (9-h 15-min photoperiod). Data were normalized across time within each photoperiod. Regression function calculated from LD data: leaf area $\left(\mathrm{cm}^{2}\right)=14.99+$ $(0.52 \times \mathrm{X})\left(r^{2}=0.81\right)$; from SD data: leaf area $\left(\mathrm{cm}^{2}\right)=13.10$ $+(0.40 \times \mathrm{X})\left(r^{2}=0.66\right)$.

Table 5. Regression coefficients calculated to predict single leaf area of Fuchsia xhybrida 'Dollar Princess' plants from experiments conducted during 1988 (88) and 1989 (89) to study the effect of DT, NT, and photoperiod on Fuchsia morphology. Individual leaf area was a linear function of DIF. Therefore, individual leaf area could be described by the function: single leaf area $=b_{0}+b_{1} \times$ DIF. Slopes and intercepts were evaluated using a technique outlined by Snedecor and Cochran (1967).

\begin{tabular}{|c|c|c|c|c|c|c|}
\hline \multirow[b]{3}{*}{ Coefficients } & \multicolumn{4}{|c|}{ Raw data } & \multirow{2}{*}{\multicolumn{2}{|c|}{$\begin{array}{c}\text { Normalized data } \\
\text { regression }\end{array}$}} \\
\hline & \multicolumn{2}{|c|}{ SD } & \multicolumn{2}{|c|}{ LD } & & \\
\hline & 88 & 89 & 88 & 89 & $\mathrm{SD}$ & $\mathrm{LD}$ \\
\hline $\begin{array}{l}b_{0} \\
b_{1} \\
r^{2}\end{array}$ & $\begin{array}{r}12.95 \\
0.48 \\
0.62\end{array}$ & $\begin{array}{c}10.39 \\
0.33 \\
0.75\end{array}$ & $\begin{array}{r}14.54 \\
0.58 \\
0.76\end{array}$ & $\begin{array}{r}12.68 \\
0.42 \\
0.80\end{array}$ & $\begin{array}{r}13.10 \\
0.40 \\
0.66\end{array}$ & $\begin{array}{r}14.99 \\
0.52 \\
0.81\end{array}$ \\
\hline \multicolumn{7}{|c|}{ Comparison of slopes } \\
\hline $\begin{array}{l}\text { Raw data: } \\
\text { Raw data: } \\
\text { Normalize }\end{array}$ & $\begin{array}{l}38 \text { SD v } \\
38 \text { LD v } \\
\text { data: } S\end{array}$ & $\begin{array}{l}89 \text { SD } \\
89 \text { LD } \\
\text { vs. LD }\end{array}$ & $\begin{array}{l}F= \\
F= \\
F=\end{array}$ & $\begin{array}{l}3.6 \\
2.7 \\
121.5\end{array}$ & $\begin{array}{l}(\mathrm{df}=1,31) \\
(\mathrm{df}=1,30) \\
(\mathrm{df}=1,61)\end{array}$ & $\begin{array}{l}\text { NS } \\
\text { NS } \\
* * *\end{array}$ \\
\hline \multicolumn{7}{|c|}{ Comparison of intercepts } \\
\hline \multicolumn{3}{|c|}{ Raw data: 88 SD vs. 89 SD } & \multicolumn{2}{|c|}{$F=20.9$} & $(\mathrm{df}=1,31)$ & $* * *$ \\
\hline \multirow{2}{*}{\multicolumn{3}{|c|}{ Raw data: 88 LD vs. 89 LD }} & \multicolumn{2}{|c|}{$F=6.6$} & $(\mathrm{df}=1,30)$ & $* * *$ \\
\hline & & & $F=$ & 12.43 & $(\mathrm{df}=1,61)$ & $* * *$ \\
\hline
\end{tabular}

in this experiment, increased stem elongation through one or more of these three factors.

DIF and photoperiod interacted to affect stem elongation in 'Dollar Princess' fuchsia where NI was used. We question whether the interaction between temperature and photoperiod was due to a response to light quality or light duration. Berghage (unpublished data) showed that increasing photoperiod on fuchsia via a day-extension treatment using fluorescent and incandescent lamps also resulted in a photoperiod $\times$ DIF interaction. Therefore, a DIF $\times$ photoperiod interaction is present independent of a light-quality effect on fuchsia. The data presented in the current research and those of Berghage (unpublished data) both showed a greater response of stem elongation to DIF (on a percent basis) on SD-grown plants than on LD-grown plants.

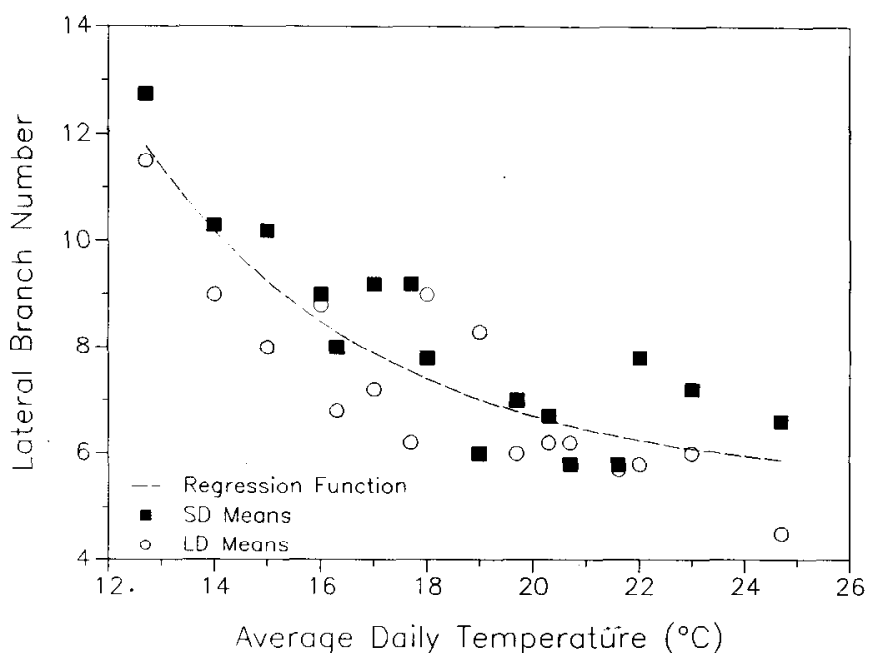

Fig. 4. Effect of ADT and photoperiod on Fuchsia $\times$ hybrida 'Dollar. Princess' branch count at anthesis on plants grown under LD (9-h 15-min photoperiod plus 4-h NI using incandescent lamps at an irradiance of $\left.2 \mu \mathrm{mol} \cdot \mathrm{m}^{-2} \cdot \mathrm{s}^{-1}\right)$ or after 78 days on plants grown under SD (9-h 15-min photoperiod) (1988 data only). The regression function calculated from the data is the exponential function: branch number $=106.28 \times \operatorname{EXP}(-0.22188 \times \mathrm{X})+5.43\left(r^{2}=0.74\right)$.

DIF strongly influenced leaf expansion. The effect of DIF on fuchsia leaf expansion contrasts with research on Lilium longiflorum, where leaf expansion was affected by NT only (Erwin et al., 1989). Earlier work by Dale $(1964,1965)$ suggested that Phaseolus vulgaris leaf expansion was greatest when DT and NT were constant, i.e., a OC DIF. Our re-examination of Dale's data (1964) showed this conclusion was based on several treatments that contained either a 30C DT or NT. Based on Dale's own data and conclusions, leaf expansion was reduced at 30C. Therefore, conclusions relating temperature effects and leaf expansion based on treatments that include 30C may be misleading. If Dale's data (1964) from environments not containing a 30C DT and/or NT are eliminated, leaf area increased as DIF increased. The greatest leaf area developed in the environment with the highest DIF that did not contain a 30C DT or NT (20C DT/10C NT). In contrast, recent research by J.E.E. and Strefeler (unpublished data) showed that Cucumis leaf expansion was greater when plants were grown with constant rather than fluctuating temperatures. Greater leaf expansion in a positive DIF environment or a constant temperature environment is probably species-dependent.

Leaf expansion is often influenced by ADT, as has been shown in Phaseolus (Dale, 1964), Cucumis (Milthorpe, 1959), and Euphorbia (Berghage, 1989). No effect of ADT on fuchsia leaf expansion was observed in the current study (data not presented).

Branching in Fuchsia decreased as ADT increased. A decrease in lateral branching as ADT increased had also been reported on Petunia (Kaczperski, 1989) and Dianthus (Moe, 1983). NI lighting using incandescent lamps has been shown to reduce lateral branching on Dendrunthema (Heins and Wilkins, 1979a), Campanula (Moe and Heins, 1991), and Dianthus (Heins and Wilkins, 1979b) when compared to plants that received no NI or a day-extension treatment using incandescent lighting. Heins and Wilkins (1979a, 1979b) suggested that the reduction in lateral shoot count was due to inhibition of lateral shoot development by FR light and/or induction of flowering, as was the case with Dianthus. Flower induction of fuchsia did not significantly affect branching in the current study. 


\section{Literature Cited}

Berghage, R.D. 1989. Modeling stem elongation in Euphorbia pulcherimma. PhD Diss.. Michigan State Univ., East Lansing.

Dale, J.E. 1964. Some effects of alternating temperature on the growth of French bean plants. Ann. Bet., N.S. 28(109):127-135.

Dale, J.E. 1965. Leaf growth in Phaseolus vulgaris. II. Temperature effects and the light factor. Ann. Bot. 29:293-308.

Draper, N.R. and H. Smith. 1981. Applied regression analysis. 2nd ed. Wiley, New York. p. 294-313.

Erwin, J. E., R.D. Heins, and M.G. Karlsson. 1989. Thermomorphogenesis in Lilium longiflorum Amer. J. Bot. 76(1):47-52.

Erwin, J.E. 1991. Thermomorphogenesis in plants. PhD Diss., Michigan State Univ., East Lansing.

Erwin, J.E. and R.D. Heins. 1990. Temperature effects on lily development rate and morphology from the visible bud stage until anthesis. J. Amer. Soc. Hort. Sci. 115(4):644-646.

Halevy, A.H. and J. Rudich. 1967. Modifications of sex expression in muskmelon by treatment with the growth retardant B-995. Physiol. Plant. 20:1052-1058.

Heins, R.D. and H.F. Wilkins. 1979a. The influence of node number, light source, and time of irradiation during darkness on lateral branching and cutting production in 'Bright Golden Anne' chrysanthemum. J. Amer. Sot. Hort. Sci. 104(2):265-270.

Heins, R.D. and H.F. Wilkins. 1979b. The effect of photoperiod on lateral shoot development in Dianthus caryophyllus L. cv. "Improved White Sun'. J. Amer. Soc Hort. Sci. 104(2):314-319.

Jones, M.G. and J.A.D. Zeevaart. 1980. The effect of photoperiod on the levels of seven endogenous gibberellins in the long-day plant Agrostemma githago L. Planta 149:274-279.

Karlsson, M. G., R.D. Heins, J.E. Erwin, R.D. Breghage, W.H. Carlson, and J.A. Biernbaum. 1989. Temperature and photosynthetic photon flux influence chrysanthemum shoot development and flower initiation under short-day conditions. J. Amer. Soc. Hort. Sci. 114(1):158-163.

Kaczperski, M.P. 1989. Influence of temperature and irradiance on growth and development of Petunia $\times$ hybrids 'Snow Cloud'. MS Thesis, Michigan State Univ., East Lansing.

Milthorpe, F.L. 1959. Studies on the expansion of the leaf surface. I. The influence of temperature. J. Expt. Bot. 10(29):233-249.

Moe, R. 1983. Temperature and daylength responses in Dianthus caryophyllus CV. Napoleon 111. Acts Hort. 141 :165-171.

Moe, R. and R.D. Heins. 1991. Control of plant morphogenesis and flowering by light quality and temperature. Acts Hort. (In press.)

Pharis, R.P. and R.W. King. 1985. Gibberellins and reproductive development in seed plants: Annu Rev. Plant Physiol. 36:517-568.

Snedecor, G.W. and W.G. Cochran. 1967. Statistical methods. 6th ed. Iowa State Univ. Press, Ames. p. 432436.

Tageras, H. 1979. Modifying effects of ancymidol and gibberellins on temperature induced elongation in Fuchsia $\times$ hybrids. Acts Hort. 91:411-417.

Vince-Prue, D. 1977. Photocontrol of stem elongation in light-grown plants of Fuchsia $\times$ hybrids. Planta 133:141-156.

Went, F.W. 1952. The effect of temperature on plant growth. Annu. Rev. Plant Physiol. 4:347-362.

Went, F.W. 1957. The experimental control of plant growth. Chron. Bot. 17. Ronald Press, New York. p. 223-226.

Wilkins, H. 1985. Fuchsia $\times$ hybrids, p. 38-41. In: A.H. Halevy (cd.). CRC handbook of flowering. vol. III CRC Press, Boca Raton, Fla.

Zieslin, N. and M.J. Tsujita. 1988. Regulation of stem elongation of lilies by temperature and the effect of gibberellin. Scientia Hort. 37:165-169. 